\title{
Heat and Gender Do Not Affect the Professor's Moral Reasoning
}

\author{
Víctor Hugo Robles Francia \\ División de Ciencias Económico Administrativas, UJAT, Villahermosa, México \\ Email:vicrob13@yahoo.com.mx
}

How to cite this paper: Francia, V.H.R. (2018) Heat and Gender Do Not Affect the Professor's Moral Reasoning. Open Journal of Social Sciences, 6, 197-207.

https://doi.org/10.4236/jss.2018.64017

Received: March 22, 2018

Accepted: April 24, 2018

Published: April 28, 2018

Copyright $\odot 2018$ by author and Scientific Research Publishing Inc. This work is licensed under the Creative Commons Attribution International License (CC BY 4.0).

http://creativecommons.org/licenses/by/4.0/

(c) (i) Open Access

\begin{abstract}
People illness by the heat is an obligated discussion lately. The heat affects the cognitive activity of people and the women are especially affected by it. So, the cognitive reasoning of the Moral Judgment is influenced by this kind of weather, and indirectly by the sex. To study the sex and heat incidence on Moral Judgment of university professors was the purpose of this research. The university professors are moral agents because they complement and supplant the family regulations and the educative precedent rules. The Moral Judgment of 212 superior education professor was registered by the Moral Judgment Test. 121 professors in a dry weather and 91 in a tropical were measured, 98 women and 114 men. The sex neither the heat explained the moral judgment level of professors. But this competence in the professors observed a low level. This suggests that actions to improve moral judgment must be made. So, the antecedents, the theory, and the findings are discussed in this article.
\end{abstract}

\section{Keywords}

Moral Judgment, Gender, Heat, University Professors

\section{Introduction}

The hot weather negatively influences on the cognitive skill during the professor's job and may impact his moral reasoning. The heat adversely affects the human cognitive skill while person is working [1]. In this sense, the heat affects the moral judgment cognitive stage, that it is a structured system, which governs the individual basic moral estimation [2].

The theory of Piaget [2] analyzed the moral judgment of the child and established that in adolescence the norms and rules acquired through the game compete with the order of adults. This author affirmed that the moral judgment is an 
individual valuation on the actions of other individuals in relation to own and, depending on this, the person acts to achieve a just relationship. Kohlberg [3] affirms that this judgment is the cognitive capacity to discriminate possible decisions and to act agree with internal principles.

The corporal affectation of hot climate in men and women has small differences [4]. Sex and age influence the maximum absorption of oxygen, which is the highest amount that the body can metabolize, commonly referred as the cardiovascular or the aerobic capacity; this capacity is lower in women than men, heat harms more the women physical capacity [5]. Then the moral judgment competence is disturbed by the hot climate and it is deteriorated more in women than men.

The adverse aftermath by the hot weather on the moral judgment of men and women, whose activity is teaching at the university level, is few investigate. The present paper evaluates the moral judgment competence in two groups of university teachers, considering the heat effect in women and men, into two different climates: the first one, dry, semi-cold and semi-humid; and the second, tropical, humid and warm.

\section{Review of Literature}

To explorer the issues surrounding heat affecting on the moral judgment competence of men and women who teach at the university level, it is important to examine the literature for answer the following questions:

\subsection{Is the Professor Moral Judgment a Cognitive Competence?}

The Organization for Economic Cooperation and Development (OECD) and the European Union (EU) suggested that the competency-based learning approach has been extended in the different educational systems since many decades ago [6]. García [7] identifies the competences in five categories: Knowing, Doing, Wanting, Living and Being. He involves personal competencies, highlighting responsibility, family, and society, recognizing that education is present in any field in which the human been develops.

University and professors expand the restrictive incidence of parents, family and previous education. They have the rol of a moral agent [8]. This moral agent incorporates new prescriptive regulatory functions; it complements and replaces their attributions. In this way, the moral reasoning of the university academics. Their moral judgment has been constituted as a key competence for the teaching task and is integrated even as a subject of institutions in teacher training [9].

The moral judgment cross through six stages into three prescriptive levels of reciprocity and justice [3] [10]: preconventional, contains stage 1 and 2; conventional, stage 3 and 4; and postconventional, 5 and 6 . The conventional term represents the appreciation of social norms, expresses conformity and respect for them. The pre and post prefixes, on the conventional expression, refer to: first is considered only the consequences of the action taken and second, the scope of 
the execution of the rules. Lind [11] sets the moral judgment as a cognitive competence, evaluated by the Moral Judgment Test MJT [12] and quantified by the $C$ index, which correlates with the kohlbergian moral stages six [11] [13]. Al-Shurai [14] conducted a study in Kuwait with 100 high school teachers, with a mean age of 28.6 years. He found a predominantly conventional reasoning of the participants in the Kohlbergian taxonomy.

\subsection{How Does the Heat Affect Cognition of the Professors' Moral Judgment?}

Heat affects professor cognitive abilities, his moral reasoning, and performance are decreased. Hajizadeh, Golbabaei, Reza, Farhang, and Ezadi [1] argue that the Climate change and global warming harm human health, temperatures above $25^{\circ} \mathrm{C}$ affect the human working capacity, and above $40^{\circ} \mathrm{C}$ the working is very complicated. In such a way, the climate perturbs the individuals' behavior; the heat especially increases the affectation on the labor performance. Hancher and Abd-Elkhalek [15] think that to feel this kind of weather affects the mental health of people; this people performance is lower than people in moderate climates are.

Kenney [16] affirms that body temperature is integrated by the internal and the periphery temperatures, when the human body faces conditions that move his thermal neutrality, such as cold or heat stresses, the organism try to control internal body temperature through physiological adjustments and this temperature is the main retro-transmission source of the brain to coordinate this control.

In neutral and comfortable environments, small amounts of water by diffusion through the skin are lost. But Nielsen [5] says that under intensive work in a hot climate, significant amounts of sweat are emitted, up to more than two liters per hour for several hours. This author ensures that a lost sweat between 600 and 700 milliliters considerably affects the working efficiency because heart rate and the internal temperature are increased. He also notes that the heat exhaustion symptom is a generalized fatigue, usually with headache, drowsiness, and nausea.

The Nielsen [5] arguments, the fatigue and the mental affectation in the tasks of the people, and the Hajizadeh, Golbabaei, Reza, Farhang, and Ezadi [1] arguments, point out that hot weather negatively impacts the cognitive abilities of workers. If the moral judgment is a cognitive competence, then, the heat negatively affects the professor's moral judgment.

\subsection{How Does the Heat Affect the Male and Female Professors?}

Nunneley [4] shows that industrial workers after the 50 years old decrease their tolerance to heat climate, because of their peripheral vasodilation and sweating reduction, among other factors. He says that there are some slight differences between the sexes in their heat dissipation mechanisms. the highest sweat rate is higher in men than in women. 
Nielsen [5] established two parameters on physiological limits, the temperature $\left(40^{\circ} \mathrm{C}\right)$ and the maximum absorption of oxygen. He argues that the men maximum aerobic capacity is greater than women in the same age stratum. Nielsen [5] established two parameters on physiological limits, the temperature $\left(40^{\circ} \mathrm{C}\right)$ and the maximum absorption of oxygen. He argues that the men maximum aerobic capacity is greater than women in the same age section. In addition, Nunneley [4] says that the women small dimensions cause have potential disadvantages for working in hot environments; the male sweating maximum rate is higher than the female. Thus, the hot weather is a variable, which along with sex (men or women), that determines the moral judgment cognition.

\subsection{The Sex, Male or Female, Determines the Level of Competence of the Moral Judgment of Teachers?}

There is a debate about moral judgment between women and men, some theorists say the level men moral judgment is higher than women, others researchers say opposite. Al-Shurai [14] conducted a study in Kuwait with 100 high school teachers, with an average age of 28.6 years. He found a predominantly conventional reasoning of the participants in the Kohlbergian taxonomy and did not discover differences between men and women.

Similarly, Nwankwo [17] investigated the role of sex in the moral judgment of 200 middle school teachers and did not find any differences between both sexes.

Equally, Al-Shurai [14] did not observe significant differences between both sexes in the 100 teachers moral reasoning level. The null differences between sexes in the moral judgment competence has also been demonstrated by Robles [18] [19], who studied various population groups, university students public and private workers.

However, Piaget's [2] research history shows that women moral judgment level is lower than men in childhood, where girls systematic play a role in the game later that male children. Perspective supported by Kohlberg [3], he says that the women moral judgment is lower than men, women have a heteronomous and selfish moral point of view. Recent researchers have refuted the Piaget and Kohlberg declarations, Wang and Calvano [20] indicate that women take decisions more ethical than men. Similarly, Bouhnik and Mor [21] declare that the female moral judgment is more developed than the male. Thus, these last authors say that women are more ethical and have a higher moral judgment than men.

Kohlberg's [3] asserts that the social role opportunities influence the moral judgment level. Bouhnik and Mor [21] support the argument that moral judgment is more developed in adolescent women. Their results in 1,048 adolescents on the internet environment, showed evidence about sex differences, where the men behavior were more immoral than women, researchers identified a significant correlation between sex and moral judgment, this judgment is more developed in women than in men. 
Milanowicz and Bokus [22] continue the debate on the sexual role; they found that 7 to 12 years old girls were more oriented to care and boys more to do justice, both towards opposite sex. Authors suggest that care and justice are terms naturalized and identified as "feminine" and "masculine" respectively. Their results suggest that sex becomes an important stimulant of moral behavior in the course of social relationships. Thus, the sex influences moral judgment, the daily moral valuations of academics are affected by the role of man or woman.

Hypothesis. The hypothesis was formed inquired into combining the two shoed framework: 1) Sex affects the moral judgment level competence of teachers. 2) The hot climate determines the moral judgment level competence of the professors.

Hypothesis. The Moral Trial Competition evaluated by the $\mathrm{C}$ index Teachers of higher education is explained by the Climate and sex.

\section{Method}

This research followed a descriptive and explanatory process, which was applied to two volunteer groups of resident teachers in two different climates; 121 in a dry climate and 91 in a tropical one. The Moral Judgment Competence was simultaneously quantified in both groups in the month of January. An experimental design was carried univariate factorial for the moral judgment competence, quantified by $\mathrm{C}$ index, and for the climate and the sex. A descriptive statistical analysis was carried out to observe the general results and inferential to test the hypothesis.

\subsection{Participants}

The participants were chosen because they were in two very contrasting climates with the following weather elements: a) Dry, semiarid. b) Tropical, wet. The Institutional Review Board criteria on the protection of human research subjects were fulfilled in this investigation.

Participants were 212 professors, 121 of a private university at the Mexico central region, with dry and semiarid climate; 91 of a superior technological institute of the Mexican southeast, in a tropical and wet climate. Participants had 40 years old and less than 20 scholar years (Table 1 ).

Public Technological Institute climate. Participant professors were in the following climate: $87.61 \%$ floodable, with dunes and flooded beach $12.13 \% 0.26 \%$. A temperature range of $26^{\circ} \mathrm{C}-28^{\circ} \mathrm{C}$, a precipitation range of $1,500-2,000 \mathrm{~mm}$, wet warm climate with abundant summer rainfall $100 \%$. The geographical distance between the superior technological Institute and the Private University was $854.9 \mathrm{~km}$ (National Institute of Statistics and Geography [23] (Table 2).

Private University climate. The temperature range was $10^{\circ} \mathrm{C}-16^{\circ} \mathrm{C}, 400-900$ $\mathrm{mm}$ precipitation, semi-dry, semi-cold, moderate 53.0\%, and summer rain higher than 4.0\% [24] (Table 2). 
Table 1. Participants' demography (source: results of research).

\begin{tabular}{ccccc}
\hline Variable & Climate & $\mathrm{N}$ & Mean & Std. Deviation \\
\hline \multirow{2}{*}{ Age } & $\mathrm{C}_{\mathrm{D}}$ & 121 & 39.58 & 10.10 \\
& $\mathrm{C}_{\mathrm{T}}$ & 91 & 36.50 & 7.44 \\
School performance & $\mathrm{C}$ & 121 & 8.88 & 0.62 \\
& $\mathrm{C}_{\mathrm{T}}$ & 91 & 9.06 & 0.68 \\
Coursed years & $\mathrm{C}_{\mathrm{S}}$ & 121 & 16.89 & 3.36 \\
& $\mathrm{C}_{\mathrm{T}}$ & 91 & 18.88 & 2.05 \\
\hline
\end{tabular}

Note: The 121 participant teachers were in a dry, semi-cold, and semi-wet climate, they had a mean age of 39.58 years with a standard deviation of 10.10 , and a mean of 16.89 with 3.36 standard deviation of scholar years. The 91 participants of the tropical climate, wet and warm, had a mean age of 36.50 years old with a standard deviation of 7.44, and a mean of 18.88 years old with a deviation of 2.05 .

Table 2. Outstanding weather differences (source: results of research).

\begin{tabular}{ccc}
\hline Variable & UP & ITS \\
\hline Weather & Semi-dry & Tropical wet \\
TempRange ${ }^{\circ} \mathrm{C}$ & $10-16$ & $25-28$ \\
Precipitation & $400-900 \mathrm{~mm}$ & $1,500-2,000 \mathrm{~mm}$ \\
$\mathrm{~N}$ & 121 & 91 \\
\hline
\end{tabular}

Note: The Superior Technologic weather is tropical wet, warm $\left(26^{\circ} \mathrm{C}-28^{\circ} \mathrm{C}\right)$, while the private university was UP seco, semihumid, semifreddo $\left(10^{\circ} \mathrm{C}-16^{\circ} \mathrm{C}\right)$, giving a difference in degrees centigrade from 10 to 12 , higher ITS than UP. Particularly on the day that both participants were evaluated, a temperature difference of $12^{\circ} \mathrm{C}, 28^{\circ} \mathrm{C}$, and $16^{\circ} \mathrm{C}$ respectively was recorded. In the geographical area of the ITS, Ih to precipitation had a 1.500 to $2000 \mathrm{~mm}$, while the UP only $400-900 \mathrm{~mm}$, providing greater contrast pluvial IT S of $600-$ $1100 \mathrm{~mm}$.

\subsection{Instrument}

The Lind's [12] Moral Judgment Test (MJT) was applied. The MJT evaluates the argumentation in the Kohlbergian stages and the consistency of participant's responses. MJT measures the Moral Judgment Competence through the $\mathrm{C}$ Index [11]. CJM items are made in a factorial design $2 \times 2 \times 6$. The three factors are included: Dilemma, pro-against, and stage. The stories are written as dilemmas, options "pro" and "against", and six arguments relating each Kohlbergian stages. Each dilemma tells the character's story, and where the respondent subject perceives behavioral rules contradictory. Initially, the respondent's point of view is asked about the right or wrong decision of the protagonist in each dilemma [12]. Next, the participant is asked to judge the arguments located in the six stages of moral reasoning: six pro and six against, of the protagonist's decision in each story, on a scale of -4 to $+4,12$ items per dilemma and 24 in total (Table 3).

\section{Results}

The moral judgment competence mean level of the 212 participating professors, measured by C index, was 13.19; the C index for the 98 females was 12.70 , and for the males, 114 was 13.90 (Table 4). 
Table 3. Fragment of the moral judgment test (Source. Lind [12]).

\section{Workers}

Recently a company fired some people for unknown reasons. Some workers think that their bosses are listening in on their private conversations through cameras and microphones in the building and using the information against them. The bosses say that they are not listening in. The workers cannot legally do anything until they can prove that their bosses are listening in on their conversations. Two workers then break into the main office and take the tapes that prove their bosses were listening in.

1) Would you agree or disagree with the workers' action How acceptable do you find the following arguments in favor of the two workers' action? Suppose someone argued they were right for $-3-2-1+0+1+2+3$ breaking in.

2) because they didn't cause much damage to the company.

3) because the company did not follow the law that says that they should not listen in, the actions of the two workers were allowed to bring back law and order.

$$
\begin{aligned}
& -4-3-2-10+1+2+3+4 \\
& -4-3-2-10+1+2+3+4
\end{aligned}
$$

\section{Doctor}

A woman had cancer and she had no hope of being saved. She was in terrible pain and was so weak that a large dose of a painkiller such as morphine would have caused her to die. During a brief period of improvement, she begged the doctor to give her enough morphine to kill her. She said she could no longer stand the pain and would be dead in a few weeks anyway. After some thinking, the doctor decided to give her an overdose of morphine.

14) Do you agree or disagree with the doctor's action...

How acceptable do you find the arguments presented against the doctor's action? Suppose someone said that he acted in a wrong

$-3-2-1+0+1+2+3$ way.

26) because the doctor broke the law. If a person thinks that mercy-killing is illegal, then one should refuse such requests from $\quad-4-3-2-10+1+2+3+4$ the patient.

Note. The MJT has two stories: Workers and Doctor, each one with 12 items, 6 "pro" and 6 "against", into a -4 until +4 scale, where the respondents strongly reject/accept.

Table 4. Index $\mathrm{C}$ of the participants, by sex and by climate of educational institution (source: Results of research).

\begin{tabular}{ccccccc}
\hline & \multicolumn{2}{c}{ UP-C $_{\mathrm{D}}$} & \multicolumn{2}{c}{ IT-C $_{\mathrm{T}}$} & \multicolumn{2}{c}{ Total } \\
\hline Gender & $\mathrm{N}$ & Index C & $\mathrm{N}$ & Index C & $\mathrm{N}$ & Index C \\
\hline Female & 61 & 11.62 & 37 & 13.80 & 98 & 12.70 \\
Male & 60 & 12.46 & 54 & 15.37 & 114 & 13.90 \\
Total & 121 & 12.03 & 91 & 14.73 & 212 & 13.19 \\
\hline
\end{tabular}

Note: In the dry weather, 121 UP professors got 12.03 points of the C index, the 61 fe-males had a value of 11.62, the 60 males obtained 12.46. In the tropical climate, the 91 TI academics obtained a score of 14.73 , the 37 females got 13.80 , and the 54 men 15.37 , respectively.

a) Proposition 1. The climatic differences affect the competence of the moral judgment of teachers was partially demonstrated.

The mean difference between the two participant groups was less than three points. The mean moral judgment competence of professor with a dry climate, 
semi-cold, and semi-wet, it was 12.03 points. While, the academics with Tropical Climate got 14.73 points, which only makes a difference of 2.7 points of the Moral Judgment Competence, C index.

b) Proposition 2. The teachers' sex effect on the moral judgment competence was partially verified. The marginal means between the two categories of sex observe a few difference of one percent. The mean value of the moral judgment competence of the female participants was 12.70 points, while for men it was 13.90 points, which makes a difference of 1.2 points in favor of male participants.

c) The hypothesis tested: The Moral Judgment Competence, C index, of University professors, was explained by the weather, dry or tropical, and by the sex.

This hypothesis was examined through a univariate analysis of variances for the dependent variable, $\mathrm{C}$ index and the two independent variables: Climate and sex; in this way, the hypothesis was not supported (Table 5).

The "Gender", "climate", and "Gender-climate" rows inform that these independent variables and their interaction do not have a statistically significant effect on the dependent variable, " $\mathrm{C}$ index", the moral judgment competence. The results of "Gender" and "Climate", there were no statistically significant difference in mean. C index, the Moral Judgment Competence, between males and females ( $p=0.449$ ); equally, there was no statistically significant differences between dry and tropical ( $\mathrm{p}=0.111$ ); and neither there was no statistically significant differences into the interaction climate-sex $(\mathrm{p}=0.819)$ (Figure 1$)$.

The female mean was almost equal in both climates and it was higher in the male group. It was observed essentially two parallel lines, between male and female participants, with a greater ordered to the origin of the male group, without effect on the competence of moral judgment. Women in a dry climate they had a value of $\mathrm{C}$ index of 11.62 to 13.80 , versus men, from 12.46 to 15.37 , a higher value of just 0.84 to 1.57 , no observed any combined effect on the $C$ Index.

The outcomes show that hot climate neither sex do not alter the moral judgment. These results do not support the precept of Piaget [2] neither of the Kohlberg [3], that the women moral judgment is less than of men. My findings contradict Wang and Calvano [20], Bouhnik and Mor [21] who argue that women have a higher moral development.

\section{Conclusions}

The purpose of this research was to observe the incidence of sex and hot weather in the Moral Judgment of university professors. It was noticed that the moral judgment of men is a little greater than that of women. However, sex did not affect their assessed level. Even, jointly, sex and hot weather did not affect the moral judgment of the teachers, supporting the null differences between the sexes of the participants found by the studies of Robles [18] [19] [25] and of Al-Shurai [14]. Contradicting the idea of Hancher and Abd-Elkhalek [15], that the cognition of people in hot climates is troubled in their performance, 
Table 5. Results of the univariate analysis of gender and climate variances (source: results of research).

\begin{tabular}{ccccccc}
\hline \multicolumn{6}{c}{ Tests of Between Subjects Effects } \\
\hline \multicolumn{5}{c}{ Dependent Variable: C index } \\
\hline Source & Type III sum of squares & $\underline{\mathrm{df}}$ & $\underline{\text { Mean Square }}$ & $\underline{\mathrm{F}}$ & $\underline{\text { Sig. }}$ \\
\hline Corrected model & $0.045^{\mathrm{a}}$ & 3 & 0.015 & 1.175 & 0.320 \\
Intercept & 3.606 & 1 & 3.606 & 281.074 & 0.000 \\
Climate & 0.033 & 1 & 0.033 & 2.568 & 0.111 \\
Sex & 0.007 & 1 & 0.007 & 0.574 & 0.449 \\
C*S & 0.001 & 1 & 0.001 & 0.053 & 0.819 \\
Error & 2.669 & 208 & 0.013 & & \\
Total & 6.403 & 212 & & & \\
Corrected total & 2.714 & 211 & & & \\
\hline
\end{tabular}

Note: $\mathrm{R}$ squared $=0.017$ (adjusted squared $\mathrm{R}=0.002$ ).

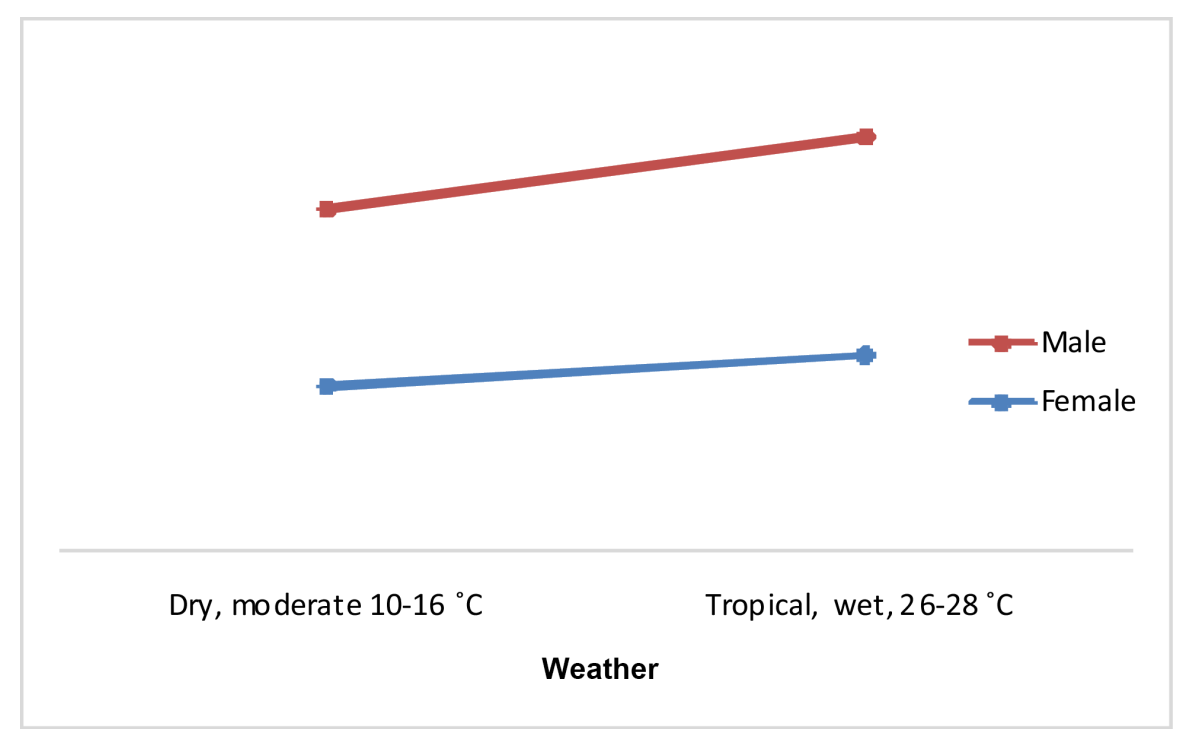

Figure 1. C Index marginal means versus the Sex and the Climate effects (source: results of research).

comparatively to those located in a moderate climate. Exposure to heat did not affect Cognitive ability, as affirmed by Hajizadeh, Golbabaei, Reza, Farhang, and Ezadi [1].

However, this research did not integrate representative samples of teachers, or concerning sexes or climate. Therefore, the results cannot be generalizable on any population.

In conclusion, the moral judgment competence of professor obtained a low level relative to other results of research conducted by Robles [19], Barba and Romo [26] and Lind [11]. Kohlberg [3] says that a moral judgment low level of professors represents a context not favorable to improve students moral judg- 
ment competence, even as a possible empathy with a low moral reasoning and an example of acting without ethical principles.

\section{References}

[1] Hajizadeh, R., Golbabaei, F., Reza, M., Farhang S. and Ezadi, E. (2014) Productivity Loss from Occupational Exposure to Heat Stress: A Case Study in Brick Workshops/Qom-Iran. International Journal Of Occupational Hygiene, 6, 143-148.

[2] Piaget, J. (1974) El criterio moral del niño. Fontanella, Barcelona.

[3] Kohlberg, L. (1958) The Development of Modes of Moral Thinking and Choice in the Years Ten to Sixteen. Disertación doctoral no publicada, Universidad de Chicago, Chicago.

[4] Nunneley, S. (1998) Prevención de estrés por calor. De Enciclopedia de Salud y Seguridad en el Trabajo, Madrid, J. Mager, Ed., Vol. 2, Cap. 42, 11-15.

[5] Nielsen, B. (1998) Efectos del estrés por calor y trabajo en ambientes calurosos. de Enciclopedia de Salud y Seguridad en el Trabajo, Madrid, J. Mager, Ed., Vol. 2, Cap. $42,5-8$.

[6] Franco Mariscal, A. (2015) Competencias científicas en la enseñanza y el aprendizaje por investigación. Un estudio de caso sobre corrosión de metales en secundaria. Enseñanza de las ciencias. Revista de investigación y experiencias didácticas, 33, 231-252.

[7] García, E. (2010) Competencias éticas del profesor y calidad de la educación. REIFPO, 13, 29-41.

[8] Shelina S. and Mitina, O. (2015) El Juicio Moral De Profesores Universitarios: Un Experimento Multifactorial Entre Dos Grupos. Russian Education \& Society, 57, 696-711. https://doi.org/10.1080/10609393.2015.1117882

[9] Johnson, L. (2008) Teacher Candidate Disposition: Moral Judgment or Regurgitation? Journal of Moral Education, 37, 429-444. https://doi.org/10.1080/03057240802405678

[10] Kohlberg, L. (1992) Psicología del desarrollo moral, Asun Zubiaur Zárate (Trad.). Desclée de Brouwer, Bilbao.

[11] Lind, G. (2004) The Meaning and Measurement of Moral Judgment Competence Revisited-A Dual-Aspect Model. In: Contemporary Philosophical and Psychological Perspectives on Moral Development and Education, Hampton Press, Cresskill, 185-220.

[12] Lind, G. (2008) The Moral Judgment Test. 12 Enero 2008. [En línea]. http://www.uni-konstanz.de/ag-moral/mut/mjt-certification.htm\#certified_versions

[13] Lind, G. (2009) Favorable Learning Environments for Moral Development-A Multiple Intervention Study With 3.000 Students in a Higher Education Context. In: Annual conference of AERA, San Diego.

[14] Al-Shurai, S. (2012) An Empirical Investigation of the Moral Judgment Development of a Sample of High School Kuwaiti Teachers. Education, 133, 340-348.

[15] Hancher, D. and Abd-Elkhalek, H. (1998) The Effect of Hot Weather on Constructive Labor Productivity and Costs. Cost Engineering, 40, 32-36.

[16] Kenney, W. (1998) Respuestas fisiológicas a la temperatura ambiente. In: Enciclopedia de Salud y Seguridad en el Trabajo, Ministerio de Trabajo y Asuntos Sociales Subdirección General de Publicaciones, Madrid, 2-5.

[17] Nwankwo, B.E. (2013) Role of Gender, Emotional Empathy, Interpersonal Attrac- 
tion on Moral Judgement. IFE Psychologia, 21, 264-276.

[18] Robles, V. (2014) Moral Judgment Competence between Public and Private Workers. A Comparative Study in Mexico. Ecorfan Journal, 5, 2073-2082.

[19] Robles, V. (2012) Complejidad De La Moralidad Organizacional: Una Discusión Sobre Diferentes Roles. Sotavento, 20, 106-117.

[20] Wang, L. and Calvano, L. (2015) Is Business Ethics Education Effective? An Analysis of Gender, Personal Ethical Perspectives, and Moral Judgment. Journal of Business Ethics, 126, 591-602. https://doi.org/10.1007/s10551-013-1973-y

[21] Bouhnik, D. and Mor, D. (2014) Gender Differences in the Moral Judgment and Behavior of Israeli Adolescents in the Internet Environment. Journal of the Association for Information Science and Rechnology, 65, 551-559.

[22] Milanowicz, A. and Bokus, B. (2013) Gender and Moral Judgments: The Role of Who Is Speaking to Whom. Journal of Gender Studies, 22, 423-443. https://doi.org/10.1080/09589236.2012.719314

[23] Instituto Nacional de Estadística y Geografía INEGI (2015) Prontuario de información geográfica municipal de los Estados Unidos Mexicanos Centla, Tabasco. INEGI, Aguascalientes.

[24] Instituto Nacional de Estadística y Geografía INEGI (2005) Prontuario de información geográfica municipal de los Estados Unidos Mexicanos Pachuca de Soto, Hidalgo Clave geoestadística 13048. INEGI, Aguascalientes.

[25] Robles, V. (2015) Nursing Curricula Are Not Enough to Improve the Students' Moral Judgment Competence. Standard Journal of Educational Research and Essay, 3,122 .

[26] Barba, B. and Romo, J. (2005) Desarrollo del Juicio Moral en la Educación Superior. Revista Mexicana de Investigación Educativa, 10, 67-92. 